\title{
Understanding the Perception of Information System Niche: Conceptualization, Measurement, and Validation
}

\author{
Mehdi Darban \\ Department of Management \& Marketing, \\ Louisiana State University-Shreveport, Shreveport, LA, USA \\ mehdi.darban@lsus.edu
}

\begin{abstract}
The number of niche technologies is growing, and they are getting noticed. However, the usage dynamics of such systems have not been explored. This study introduces the "niche" information systems (IS) construct to differentiate between mainstream and niche technologies and to illustrate how such differences potentially influence a person's IS usage behavior. We posit that niche-ness is perceptual, and a measurement to gauge an individual's niche perception in the domain of systems usage is desired. Resting on Optimal Distinctiveness theory, the study develops a novel conceptualization and operationalization of niche technology perceptions, focusing on social networking systems. Our main contribution includes the examination of the typology of the perceived niche, which results in the development and validation of an eight-item instrument for perceived technology niche through three studies. In addition, by placing the construct in a nomological network in a fourth study, we demonstrate that the perceived technology niche construct is related to IS continuance intention.
\end{abstract}

Keywords: Niche systems, perceived niche, conspicuousness, uniqueness, digital extended self, scale development.

\section{Introduction}

In the past two decades niche products, that is, highly individualized and tailored products designed to address the needs of select user groups instead of the mass market, have increasingly attracted people (Fogliatto, et al., 2012; Schaefers, 2014; Tan et al., 2017). Information systems (IS) artifacts have experienced such a trend in some cases. The advent and successful introduction of niche social networking services (SNSs), such as Clubhouse, Behance, Ello, Flixster, and ResearchGate, serve as good examples of this phenomenon. The users of mainstream SNSs, like Facebook and Instagram, are being attracted by these niche alternatives. For instance, recent reports reveal that people are leaving Facebook to join other less mainstream SNSs (Whitehead, 2020).

Niche systems are designed to lure a select cluster of users dedicated to a particular activity or topic and gather them together. The highly specialized and specific feature characteristics of such systems target smaller masses of people for the advantage of less rivalry and higher prices. However, niche systems have the potential to grow and develop into a broader market over time (Kolter \& Keller, 2006). Therefore, a successful niche product can be in a better competitive position when the niche market expands. For instance, Apple introduced the iPad as a niche product, which ultimately grew into a mass-market product (MacMillan, 2012).

IS literature has mainly examined the adoption dynamics of mainstream systems and applications. The growth in the eminence of niche systems versus mainstream alternatives calls for an exploration of the concept of a technology niche. To better illustrate the usage 
patterns of niche systems, it is important to examine how users perceive the IS niche. However, an IS research agenda on niche systems has yet to emerge, and the concept perceived as IS niche has not received empirical attention.

This study addresses this gap by focusing what is meant by "niche technology," explicitly in the SNSs' settings, and develops an instrument to measure a person's perception of the IS niche. In doing so, we delineate the domain of the technology niche and offer a multidimensional conceptualization and operationalization for the new construct. Therefore, this research contributes to the IS literature by developing a platform for future exploration of how niche characteristics of a technology influence success and acceptance of the system. Thereby, we unified the domains of consciousness, uniqueness, and digital extended self with IS consumption to improve our understanding of the usage dynamics of niche systems.

The scale would benefit systems designers in the creation and continuous monitoring of niche systems. As for practitioners, how niche users view a product is both a main factor of differentiation from others (Kapferer, 2012) and a central driver of usage (Vigneron \& Jouhnson, 2017). Presently, there is no instrument rating the perceived niche of an IS, or a clear description of what constitutes a niche versus a non-niche IS.

We begin by providing a brief review of the perceived niche construct, its conceptualization, and dimensions. Then, through four studies, we develop and validate our proposed scale for the technology niche at the individual level. Finally, the key findings of the research are reviewed and discussed.

\section{Background: perceived niche}

Optimal Distinctiveness theory (ODT) advocates that individuals reconcile conflicting needs for differentiation and assimilation through group memberships (Brewer, 1991). This literature suggests that people have a fundamental need to defend their distinctiveness and individual identities while also having a desire to belong to social groups. Individuals apply strategies to settle these opposing needs. One common strategy is to form high perceptions regarding a product they are using or a community they are joining. For instance, they may perceptually enhance how niche an SNS is to convey their membership to a select group of SNS users. Hence, the niche-ness of an IS is not automatically ingrained in its structural reality but may be perceived in the mind of individuals and be sensitive to the social setting (Berger \& Heath, 2008).

Research on conspicuous consumption - people's propensity to acquire and exhibit exclusive goods - provides further explanation for the above argument. For instance, Schaefers (2014) posits that using niche products, defined as products possessing a higher degree of specificity than corresponding mass-market alternative products, is a means to address one's need for a promoted social standing. Individuals are more likely to use niche products to express themselves than mainstream ones, which are unlikely to allow a person to express her/his identity (Berger \& Heath, 2008). Hence, there is agreement in the literature to regard niche products as products that, as they are acquired and consumed, bring reverence to the person, apart from their functional utility. Put differently, niche products enable users to fulfill both psychological and functional needs. Extending this notion to the context of SNSs, we may contend that niche SNSs satisfy the functional needs of a specific group of users (e.g., establishing collaborative research for researchers and scientists through ResearchGate) and 
may also address users' psychological desire to stay distinct from other professionals (i.e., a researcher rather than a typical professional (Brewer, 1991)).

The extant literature considered that an IS artifact is either niche or not niche, that is, mainstream. While, as we cited above, ODT implies that the sense of niche-ness of an IS product could be perceptual (Berger \& Heath, 2008). It is sensible to argue that not all niche products are equally niche. Likewise, the same product's level of niche attribute may be rated differently by different individuals. For instance, as Kemp (1998) mentions "water" could be perceived by some observers as a niche product and by some as a necessity, contingent upon who wants water or why. Interestingly, in different situations, the same product could be either a niche or a necessity for the same person (Vigneron \& Johnson, 2017).

Accordingly, a user might perceive a system as highly niche while another person may view it as mainstream. Also, we may observe a difference between niche IS associated with an upper range and those associated with the lower range of niche. For example, some SNSs may be outlined as niche systems, but all those SNSs may not be perceived niche, equally. LinkedIn could be a niche SNS across the general population as it is for professionals and relatively specific social activities (e.g., finding a job). While ResearchGate, compared to LinkedIn, may be perceived as more niche, since it is for a particular cluster of professionals (i.e., researchers).

\subsection{Perceived niche dimensions}

To the best of our knowledge, there is no investigation into niche IS. Hence to study the domain of niche systems, focusing on SNSs, we started with reviewing the relevant literature and conducting a series of qualitative research efforts, including focus group interviews and subsequent validation studies.

Reviewing psychometric works niche marketing strategies, status-seeking, and conspicuous consumptions (Dogan et al., 2018; Echols \& Tsai, 2005; Parrish, 2010; Vigneron \& Johnson, 2017), we proposed a conceptual framework to measure perceived system niche (Figure 1). The extant research argues that apart from personal motivations of consumption and usage behaviors, the interpersonal and external factors, such as social membership groups, derive those behaviors (Darban \& Polites, 2020; Roux et al., 2017). This conceptualization of perceived niche that the construct has two orientations, i.e., personal and interpersonal, is in accordance with the central tenet of ODT. The theory argues that in defining their identity in relation to others, people strive to achieve a balance between the interpersonal and personal motives derived from ingroup-outgroup categorization (Brewer \& Pickett, 2014). Accordingly, we incorporated the personal and interpersonal dimensions in our developed description of the construct. It helped us establish a balance between these two groups of niche consumption motives for our conceptualization of niche construct, which reflects both ingroup and outgroup needs. This approach is consistent with previous research on status-directed consumption, as it demonstrated that consumption behavior varies between people depending on their susceptibility to personal and interpersonal influences (Vigneron \& Johnson, 2017).

Following the literature, we included "consciousness" and "uniqueness," which represent interpersonal values (e.g., Amaldoss \& Jain, 2008) and "digital extended self," which reflects personal motivations (e.g., Villanova, 2019). Hence, our subsequent qualitative and quantitative scale development efforts provide initial support to the proposed conceptualization of the perceived niche. 


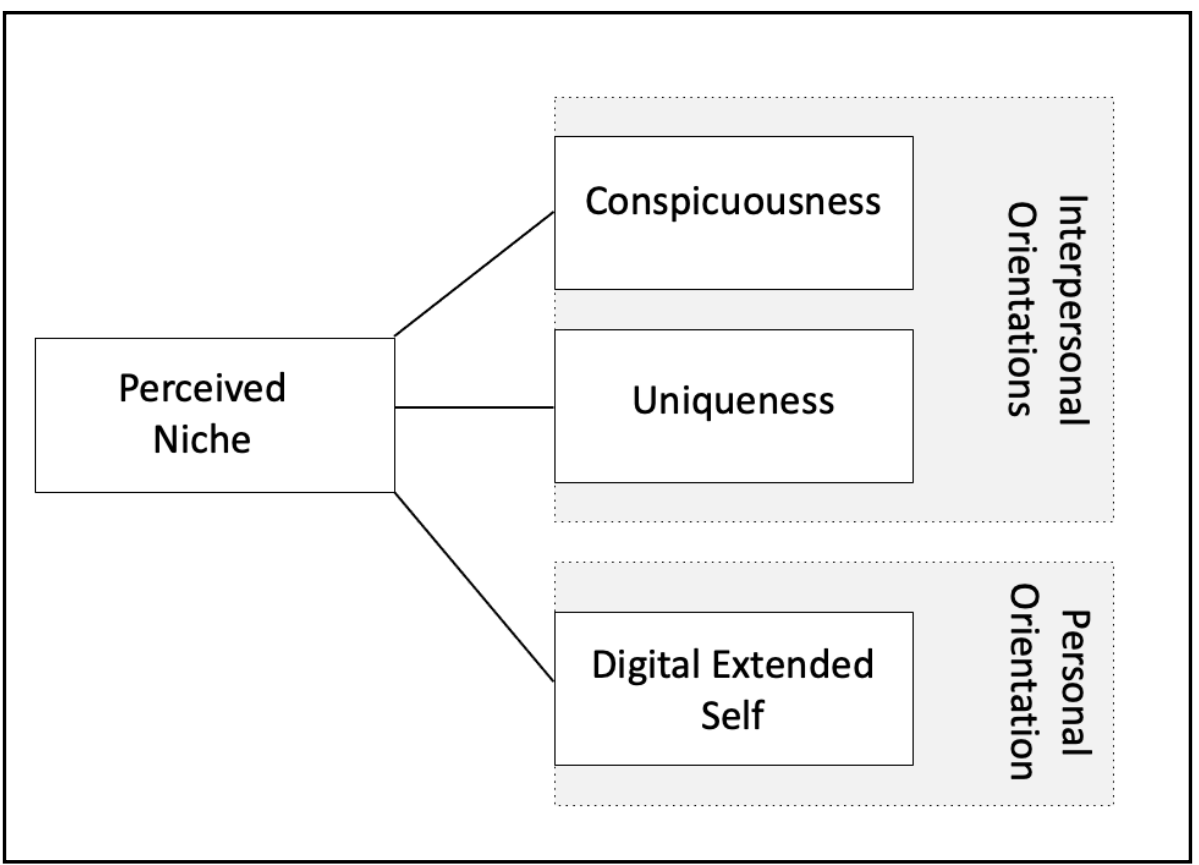

Figure 1. Framework of perceived niche index

\subsection{Conspicuousness}

Conspicuousness refers to a product's value-expressive aspect (Bajac et al., 2018). People develop desires for conspicuous consumption, such as using niche products, to influence others' perceptions about themselves (Brewer, 1991; Patsiaouras \& Fitchett, 2012). Therefore, SNS users would prefer niche alternatives to signal their status. As niche SNSs might be seen as less known and elite products, unlike mainstream SNSs, their use could be a mechanism for satisfying user's interpersonal motives, such as yearning for status-signaling (Schaefers, 2014). Therefore, the use of niche products can address the users' functional needs better than corresponding mainstream alternatives and also transmit a symbolic meaning (Gierl \& Huettl, 2010). Thus, the conspicuousness aspect of a niche system lets the user be noticed and expressed.

\subsection{Uniqueness}

Uniqueness refers to the extent to which a product is distinct from products in the same category (Cho \& Suh, 2020). Prior studies, including research on uniqueness (Snyder \& Fromkin, 2012), intergroup differentiation (Jetten et al., 2004), and optimal distinctiveness (Brewer, 1991), argue that people deviate from similar others. Specifically, the uniqueness literature posits that individuals may resist conformity as too much similarity leads to negative emotional reactions (Snyder \& Fromkin, 2012). To mitigate this unwelcome state, they tend to differentiate themselves. Hence, people susceptible to interpersonal influences may prefer to drop mainstream products in favor of more niche ones to enhance their social images (Wan et al., 2018). Schaefers (2014) points out that the use of niche products might be a strategy to improve a person's social image and communicate her/his uniqueness. Prior research found that the scarcity, as opposed to the popularity, of a product enhances the perceived uniqueness of it, which may drive user's preferences for that product (Pantzalis, 1995).

Similarly, in the context of SNSs, the uniqueness dimension of niche refers to the concept of exclusivity, which may attract the SNS user who loses interest in mainstream and popular 
products (Vigneron \& Johnson, 2017). We observe that niche SNSs are designed for an exclusive group of users, rather than for the general population. For instance, while Facebook is designed for (almost) everyone, Ello is for SNS users who have interest in digital art.

\subsection{Digital extended self}

SNS users may prefer a niche system because of its symbolic meaning (Wang \& Lee, 2020). A product must have a symbolic meaning to enable users to express status clearly. Such systems offer the possibility for a user to extend the self by integrating symbolic meanings into their identities, which results in the creation and enhancement of the self (Belk, 1988). Specifically, the identity-relevant products (vs. neutral ones), such as SNSs (Wang et al., 2020), provide greater capacity to signal one's identity (Ferraro, et al., 2011). The concept of extended self indicates that individuals view their group membership, or being part of a users' cluster of specific SNSs, as part of their identity (Parkinson et al., 2018).

Belk (2018) updated the concept of extended self to the IS realm by introducing digital extended self. In the pre-digital age, we could try out new identities by owning specific clothes or cars, while in the present digital era, our online virtual appearance offers a more accessible and safer context for such self-experimentation. Belk noted that an affiliation with certain virtual communities might be perceived as an extension of a person's real self. Similarly, adopting a specific system, like a niche SNS, may create a context for a person to fully represent his/herself and form the sense of virtual self. Therefore, the creation and the communication of the desired extended self, play a significant role in motivating a person to use a niche product.

\begin{tabular}{|l|l|l|l|}
\hline \multicolumn{1}{|c|}{ Stage of scale development } & \multicolumn{1}{|c|}{ Sample } & \multicolumn{1}{c|}{ Details } & \multicolumn{1}{c|}{ Results } \\
\hline $\begin{array}{l}\text { Study 1 - Preliminary } \\
\text { qualitative data collection }\end{array}$ & $\begin{array}{l}\text { Business students } \\
(n=27)\end{array}$ & $\begin{array}{l}\text { Literature review \& } \\
\text { Focus group sessions }\end{array}$ & $\begin{array}{l}\text { List of 22 candidate } \\
\text { items }\end{array}$ \\
\hline Item generation & Expert judges $(n=4)$ & Face validity & $\begin{array}{l}22 \text { items reduced to } \\
11 \text { items }\end{array}$ \\
\hline Q- sort & Expert judges $(n=8)$ & $\begin{array}{l}\text { Item replacement ratios } \\
\text { and Kappa (Construct } \\
\text { validity) }\end{array}$ & $\begin{array}{l}11 \text { items reduced to } \\
10 \text { items }\end{array}$ \\
\hline $\begin{array}{l}\text { Study 2 -Initial longitudinal } \\
\text { validation study }\end{array}$ & $\begin{array}{l}\text { Amazon's MT }(n=180) \\
\text { at two time period, } 8 \\
\text { weeks apart }\end{array}$ & $\begin{array}{l}\text { EFA, Reliability, } \\
\text { Discriminant and } \\
\text { Convergent validity, CFA }\end{array}$ & $\begin{array}{l}10 \text { items reduced to } \\
8 \text { items }\end{array}$ \\
\hline $\begin{array}{l}\text { Study 3 -Longitudinal } \\
\text { validation and establishment } \\
\text { study }\end{array}$ & $\begin{array}{l}\text { Amazon's MT }(n=353) \\
\text { at two time periods, } 8 \\
\text { weeks apart }\end{array}$ & $\begin{array}{l}\text { Reliability, Discriminant } \\
\text { and Convergent validity, } \\
\text { CFA }\end{array}$ & Final list of 8 items \\
\hline $\begin{array}{l}\text { Study } 4-\text { Nomological } \\
\text { validity testing }\end{array}$ & $\begin{array}{l}\text { Amazon's MT }(n=308) \\
\text { at three time periods, } 8 \\
\text { weeks apart }\end{array}$ & $\begin{array}{l}\text { Predictive validity, } \\
\text { Structural equation } \\
\text { modelling }\end{array}$ & $\begin{array}{l}\text { Establishment of } \\
\text { nomological validity }\end{array}$ \\
\hline
\end{tabular}

Table 1. Summary of the scale development process

\section{Scale development}

The study developed and validated the scale, basing on grounded theory approach and following the procedure recommended by Moore and Benbasat (1991). As pointed out by Nayal and Pandey (2020) grounded theory facilitates the domain exploration and scale development of the novel phenomenon. In study 1, we started with a review of the relevant literature followed by a qualitative data collection. Then, we created an initial set of items in the item generation step. Later, we conducted Q-sort analysis. Finally, via three empirical studies, we validated the instrument. Table 1 provides an overview of the entire process. 


\subsection{Study 1 - Preliminary qualitative data collection: focus groups}

Since there has been limited research on niche technology, we conducted a series of interviews to explore the domain of individuals' niche perceptions. Participants were from a large Midwestern university (27 students: 12 females and 15 males, median age 24 years old), and they were active users of niche technologies (e.g., augmented reality apps, ResearchGate, Behance). At the first phase in the focus group sessions, we employed open-ended questions to capture personal description of niche from the perspective of our sample. Some examples are: "How does a niche app satisfy your needs differently from a less niche one?", "Why do you feel some SNSs are more niche than others?" and "What does compel you to use more niche IS?."

Then, the researchers and assistant moderators met to discuss the transcripts to detect preliminary themes and aspects related to niche technology perceptions. It initially resulted in 25 statements, which were reviewed and reduced to 22, reflecting the 3 aspects of the perceived niche construct $(7$ reflecting conspicuousness, 8 reflecting uniqueness, and 7 reflecting digital extended self) (Figure 1). We did not find any clear and distinct theme reflected by the eliminated three statements. Therefore, we concluded that those three statements were not directly and accurately representing any aspect of the perceived niche construct.

According to the results of Study 1 and building on Porter's (1980) generic strategic approach and other relevant studies which we reviewed in previous sections (e.g., Echols \& Tsai, 2005; Parrish, 2010; Vigneron \& Johnson, 2017), we conclude that niche technologies represent three dimensions of consciousness, uniqueness, and digital extended self. These three aspects refer to the main defining criterion for a niche technology, that is "specificity." Hence, the perceived IS niche is defined as a user's belief about the degree of specificity of the attributes of technology.

\subsection{Item generation and expert review}

We intended to develop a short, easy-to-administer instrument. We sought to conceptualize perceived niche as a reflective, second-order construct. It is because we were interested in a predictive and simple scale for the construct, rather than in the unique properties of its different manifestations. Hence, we developed an instrument in which items reflecting the dimensions of the construct were aggregated into a single score. This conceptualization corresponds to what Bagozzi and Heatherton (1994) call the total aggregation model of perceptual construct measurements. Formative, rather than reflective, conceptualization may cause overall scores on the scale to be psychologically unclear, and the relations between perceived niche scores and other variables become challenging to interpret (see Bagozzi \& Heatherton,1994). Besides, prior research reveals that there should be high levels of covariation across the identified dimensions of perceived niche (e.g., Franke \& Schreier, 2008), which supports that the construct is reflective (Jarvis et al., 2003).

To generate the items, we followed a multistep procedure to develop the instrument (Straub et al., 2004). Firstly, a pool of potential items (22 items) for measuring perceived niche was created based on our qualitative focus group interviews, the definition of the construct, and extant literature. Then, four IS and management academics evaluated the instrument and deleted some items with poor face validity. In total, 11 items: three items reflecting conspicuousness, four items reflecting uniqueness, and four items reflecting digital extended self, were selected. 


\subsection{Q-sort analysis}

To map items dimensions, four judges (doctoral students of IS) in each round participated in two-step Q-sorting procedures (Moore \& Benbasat, 1991). In the first round, the judges could create as many groups as they want but were required to name the resulting groups. In the second round, four different judges were given the name and description of the focal construct dimensions and a fourth "too ambiguous/does not fit" category. Then, they assigned the cards to those four categories.

To assess construct validity, we examined the item-placement ratios, as described by Moore and Benbasat (1991). If an item is consistently placed into its intended category, we may be confident that it has high construct validity. To further evaluate the reliability of the sorting by the judges for each pair of judges in each sorting step, we measured their level of agreement in categorizing by calculating Cohen's Kappa (1968). Kappa scores higher than 0.65 are considered acceptable.

\subsubsection{Q-sort results}

In the first round, two judges created three categories, while the other two had four, resulting in an overall item placement ratio of $64 \%$ and an average Kappa score of 0.63 . In this round, one item was dropped from the item pool because it was found to be too ambiguous (fitting in an unintended category) by two judges.

A second card sorting confirmed 10 items mapped to their corresponding dimensions of perceived niche. The overall item placement ratio within the target construct for the second round was improved to $76 \%$, and the average Kappa score increased to 0.88 . Thus, we concluded that the developed scale demonstrated construct validity, with a high potential for acceptable reliability coefficients.

\section{Assessment of the scale}

\subsection{Research technology}

We conducted two longitudinal and one nomological studies to assess the developed scale. Ello (Studies 2 and 3) and Behance (Study 4), two SNSs, were the research technologies. Based on their published manifestos, in sharp contrast to other mainstream SNSs (e.g., Facebook), these two social networking tools do not perform data mining to turn their users into products (Ello Manifesto, 2014). Additionally, they are designed to attract a specific segment of SNS users interested in digital art. For instance, the creator of Ello, Paul Budnitz, expressed: "We don't want everyone on Ello. That's not what we're building" (Shea, 2018). Also, they offer some features for purchase, such as the ability to have multiple profiles. Hence, we argue that these two, relatively new SNSs, qualify as niche technologies with the potential for observing acceptable levels of variance in their users' niche perceptions.

\subsection{Study 2: Initial validation study}

This study assesses the discriminant and convergent validity of the generated measurement. We recruited 203 participants from Amazon's Mechanical Turk (MT), resulting in a usable sample of 180 participants. Fifty six percent of the respondents were female, and the median age was 33 years old, and the median education was college degree.

The participants were provided with the URL of the first survey questionnaire (i.e., demographic questions). Then, they were asked to create an account on Ello to participate in 
the second phase of data collection. They provided their user IDs for later screening. Eight weeks later, the respondents to the first survey were invited to participate in the second survey. They confirmed they had used the system. Additionally, we checked the provided user IDs and their activities on Ello to ensure the participant had interacted with the system. We dropped 23 responses for not using the system during the previous eight weeks and data quality (e.g., speeding through a survey). Then, the respondents completed the second survey, which included the developed scale of perceived niche. We used 7-point Likert scales, with 1 representing "strongly disagree," 4 "neutral," and 7 "strongly agree."

\subsubsection{Analyses and Results}

An exploratory (principle components) factor analysis (EFA) using Varimax rotation in SPSS was conducted to assess the reliability of the scale (Moore \& Benbasat, 1991). Then, we estimated a confirmatory factor analysis (CFA) to further confirm the validity, reliability, dimensionality, and second-order factor structure of the instrument. To enhance the rigor of our assessments and ensure that items were strictly measuring niche perceptions, we included measures for related variables such as Network effect (e.g., The more people use Ello, the more valuable it is to users), confirmation (e.g., Compared to my initial expectations, the ability of Ello to improve my performance was much better than expected), task-technology fit (e.g., Ello's functions are very sufficient).

\begin{tabular}{|l|l|}
\hline \multicolumn{2}{|l|}{ Conspicuousness (CN) } \\
\hline CN1 & Ello is designed for an elite cluster of SNS users. \\
\hline CN2 & I use Ello because it enhances my social image. \\
\hline CN3 & Ello's content reflects its high status. \\
\hline Uniqueness (UQ) \\
\hline UQ1 & Ello is distinct from other SNSs. \\
\hline UQ2 & Ello can be used in a different way compared to other SNSs. \\
\hline UQ3 & There are characteristics that are specific to Ello. \\
\hline UQ4 & Ello's content is different from other SNSs'. \\
\hline Digital extended self (DG) \\
\hline DG1 & I can relate Ello to my identity. \\
\hline DG2 & I can express myself fully using Ello. \\
\hline DG3 & Ello allows me to express myself the way I could not by other SNSs. \\
\hline
\end{tabular}

Table 2. SNS Perceived Niche Instrument

Note: Items UQ3 and DG1 were dropped due to low item loadings.

Our factor analysis confirmed the factor structure, discriminant, and convergent validities of the instrument (see Table A1 in Appendix A). Loadings greater than 0.707 are considered adequate (Chin, 1998). Two items with low loadings (one reflecting "uniqueness" loading at 0.61 , and one reflecting "digital extended self," loading at 0.54 ) were removed with the content validity in mind. The subsequent factor analysis indicated that the selected eight items loaded on the relevant dimensions. The CFA results of the initial 10-item and the purified 8-item measurements further supported removing those two items (see Table A2 in Appendix A). In Table 2, we provide a complete listing of all items and their corresponding dimensions of perceived niche retained for the final version of the scale.

To evaluate the second-order conceptualization, we estimated three models (Table 3): unidimensional, and three freely correlated factors, and a second-order model. The results of comparisons across models indicate that the second-order model that considers SNS niche as 
a second-order construct with three reflective first-order factors better illustrates the relationships in our data (Thatcher, et al., 2018).

\begin{tabular}{|l|c|c|l|}
\hline \multicolumn{1}{|c|}{ Model } & \multicolumn{1}{c|}{$\chi^{2,} \mathbf{d f}$} & CFI & RMSEA \\
\hline Unidimensional (1st order factor) & $415.19,20$ & 0.68 & 0.217 \\
\hline Three freely correlated (1 ${ }^{\text {st }}$ order factors) & $36.62,17$ & 0.95 & 0.085 \\
\hline Second-order construct & $21.87,17$ & 0.98 & 0.040 \\
\hline
\end{tabular}

Table 3. Second-Order Model Comparisons for Perceived Niche

Moreover, we assessed the reliability and average variance extracted (AVE) values, following Fornell and Larcker (1981) (see Table A3 in Appendix A). The Cronbach's alpha and composite reliability of the scale exceeded the 0.70 thresholds (Nunnally \& Bernstein, 1994). Although the dimensions of perceived niche were found to be correlated, each dimension's AVE exceeded the squared correlations between all other dimensions. It indicates that dimensions form conceptually related, yet discriminant, portions of a superordinate second-order construct (Polites \& Karahanna, 2012; Thatcher et al., 2018).

Overall, Study 2 developed an eight-item scale of perceived SNS niche and provided preliminary confirmation of scale reliability and validity. We used the final version of the scale in a large-scale validation study (Study 3 ).

\subsection{Study 3: Validation and establishment study}

A validation study was conducted to confirm the measurement model. Like Study 2, we conducted a longitudinal (i.e., two surveys) data collection through Amazon's MT. Ello was the research technology. Respondents at Time1 were invited to participate in the second survey. Out of initial 420 participants, 353 participants provide data suitable for analysis. Forty three percent of the respondents were female, and the median age was 33 years old, and the median education was college degree.

\subsubsection{Analysis and Results}

The CFA results confirm that all items' loadings on their respective constructs were greater than the suggested threshold of 0.707 (see Table A2 in Appendix A). The composite reliability estimates ranged from 0.83 to 0.91 , while the AVEs ranged from 0.61 to 0.76 , indicating acceptable convergent validity (Bagozzi \& Yi, 1988). Also, discriminant validity was established based on the values for the square root of AVE for each construct, exceeding its correlations with other constructs in the model (Chin, 1998). The measurement model offered good fit to the data $\left(\chi^{2}=39.70, \mathrm{df}=17, \mathrm{CFI}=0.98, \mathrm{RMSEA}=0.05\right)$.

\subsection{Study 4: Assessing the nomological net}

We evaluated the predictive validity of the developed perceived niche scale vis-à-vis postadoption system use. Specifically, we tested the association between SNS perceived niche and system continuance use intention (Bhattacherjee, 2001). Consistent with game theory research, the conspicuousness and uniqueness of a product can promote its value and consumers' usage intentions (Snyder \& Fromkin, 2012). Similarly, based on Belk's (1988) theory of the extended self, Ferraro et al. (2010) posit that identity-relevant products, such as SNSs, promote usage motivations. These arguments have been validated in the context of online shopping and reviews (e.g., Lee et al., 2015). Therefore, an examination of system use is relevant to further assess the predictive validity of the scale. We expect that perceived niche positively influences 
a person's continuance use intention, defined as whether a person plans to use a familiar technology in the future.

We followed the same procedures as Studies 2 and 3 in collecting our data. As discussed earlier, Behance was the research technology. We added a third data collection phase, Time 3 survey, to measure continuance intention adapting items from Bhattacherjee (2001). Moreover, we controlled for the two constructs linked to system use by including perceived usefulness, perceived ease of use, adapted from Davis (1989), and measured in Time 2 (see Table A4 in Appendix A). Out of the initial 360 respondents, 308 provided usable responses to all three surveys. Forty six percent of the respondents were female, median age 29 years old, and median education college degree. We employed structural equation modeling.

\subsubsection{Analyses and Results}

The results for the measurement model support the validity and reliability of the measures (see Table A5 in Appendix A). Although, the longitudinal nature of the study reduces the concern with common method bias (CMB), we statistically addressed the possible effect of CMB (Sharma et al., 2009). We included an unmeasured latent method factor to CFA and let the items to load on both their theoretical constructs and the third factor (Bagozzi, 2011). It resulted in only nine percent of the common variance value.

We used AMOS 25 to test the structural model, and the results confirmed the structural model. Perceived niche has significant impact on the dependent variable $(\beta=0.33, p<.001)$. This finding verifies the relevance of perceived niche to SNS usage behavior and supports our argument (See Figure 2).



Figure 2. Results of Model Testing

\section{Discussion}

This paper is a conceptual and empirical attempt to understand users' perceptions of IS niche. The conducted four studies address the requirements to develop and validate a measurement for the perceived niche construct. Specifically, we validated perceived niche against related concepts such as task-technology fit, confirmation, and network effect, in Study 2. We confirmed this finding in study 3 with larger sample size. Moreover, in Study 4, using a different research technology, we showed that perceived niche significantly predicted 
continuance usage intention. Our results suggest that domain-specific technology niche measurement provides an acceptable level of explanatory power.

Our multi-stage and multi-study research design, in which each study investigated perceived technology niche scale from different aspects, should promote confidence in our findings. The results of the conducted studies supported the proposed second-order conceptualization of perceived technology niche, which reflects the robustness of our operational definition and theoretical foundations for this new construct.

\subsection{Theoretical Implications}

The findings of this research contribute to the broader literature on IS consumption and, in particular, to the growing literature on niche IS. Prior research exploring IS consumption has failed to recognize the niche characteristic of technology, whereas characteristics of a system, as experienced by individuals, would potentially impact their adoption decisions (Darban \& Polites, 2020; Rogers, 2003). Hence, our findings extend research on IS adoption and usage by providing an updated and comprehensive investigation into the "technology niche" concept.

An important contribution of this study is to delineate the domain of the technology niche. Our research is the first dedicated effort to propose and validate a multidimensional scale of IS niche. The adopted multi-study design should inspire confidence in our findings. We conceptualized the perceived niche as a phenomenon with three latent dimensions reflecting on interpersonal-oriented perceptions, that is, conspicuousness and uniqueness, and on personal-oriented perception, or the digital extended self. Each of the three empirical studies supported our subordinate second-order conceptualization of the technology niche. It illustrates the robustness of our operational and theoretical descriptions of this new construct and demonstrates the implication of the findings to future research. It is important to note that the perception of niche dimensions discussed and identified here represents a comprehensive set of factors that may influence individuals' IS behaviors (e.g., adoption and usage).

Moreover, we contribute to theory by developing a scale that potentially will assist researchers in investigating the role of niche perceptions in technology, and more specifically, in the SNSusage settings. The forthcoming demise of some mainstream SNSs and recognition of more niche systems (e.g., Flixster and Letterboxd), is a phenomenon, which is worthy of further examinations via measuring the effect of relevant variables, such as "perceived niche." Due to the advent of such niche SNSs, it would be interesting to examine the dynamics of individuals' adoption of those technologies. To the best of our knowledge, niche technology usage behaviors of individuals (e.g., adoption and post-adoption outcomes) have not been studied in prior IS research. By developing and validating a short, but accurate, measurement, this study provides the IS researchers with a usable and suitable tool for further exploration of the implications of the niche concept for technology use.

Finally, the developed scale has the potential to further increase the theoretical and practical understanding of the influence of technological characteristics, that is, the degree of technology niche, on an adopter's IS usage behavior. In other words, theoretical models aimed at understanding why people prefer niche systems, rather than mainstream alternatives, can be empirically analyzed through the developed scale.

\subsection{Practical Implications}

The perceived technology niche instrument is a valid and reliable tool for measuring the influence of this neglected, however emerging, technology attribute on user's interaction with 
a system. The scale introduced in this study would allow system designers to measure the niche-ness of their current or prototype products. Armed with an enhanced understanding of how their systems are being perceived by the users, they could revise their prototype system or adopt more effective marketing actions. For instance, we showed in Study 4 that perceived niche is positively associated with continuance intention; therefore, by influencing how the users view the system in terms of nichness, in other words, improving the niche perceptions among the users, managers can extend the lifecycle of their systems.

Besides, the second-order operationalization of the construct offers a finer-grain understanding of how dimensions of technology niche shape niche-ness perception. Our conceptualization of the construct suggests that system designers should be mindful in addressing all three aspects of technology niche-ness in order to position their products as a niche, rather than a mainstream system, if desired.

Moreover, future researchers, by incorporating the role of perceived niche in their models, may help system designers identify what characteristics of the system lead to higher levels of perceived niche and what initiatives can lead to higher perceived niche levels during the implementation of the new information systems. It is particularly important for SNSs, as such systems are susceptible to abandonment (Samhan, 2018). Hence, SNS designers should demonstrate and convey its niche-ness to its consumers, effectively.

\section{Limitations and Future Research}

Our study has several limitations. We studied perceived niche using two different SNSs and separate samples. Future studies should consider exploring perceived niches in more complex technologies and the broader settings of social systems. Further research is encouraged to assess the utility of the scale in other types of technologies with different characteristics and technology settings. For instance, our focus was on the voluntary use of a system, so results may contrast if examining mandatory technology usage, for example, as is the case with Yammer, an organizational enterprise system (Venkatesh et al., 2003). Also, our research context was SNSs. Therefore, the developed scale was tested on this specific type of system. Future research is needed to assess the utility of the scale in other and more complex technology use contexts and software types, such as enterprise resource planning (ERP) systems, including other sample populations, like working adults versus Amazon's MT. Researchers should examine the implications of these boundary conditions on the power of perceived niche regarding different types of IS use.

Another potentially fruitful avenue of research would be further examining the link between technology niche-ness and different types of post-adoptive system use, for example, abandonment, deep use, and active use. For instance, as Samhan (2018) pointed out, some systems, including SNSs, are prone to be abandoned by their users after an initial success, due to the stress associated with using an SNS (Maier et al., 2015), and it would be interesting to explore how the system's perception of niche can influence such post-adoptive outcomes.

\section{Conclusion}

Our studies contribute to IS research by conceptualizing "perceived niche" and establishing and validating a scale to operationalize the construct. IS research on niche technologies has not emerged, despite the recent advent and popularity of niche systems. Our research is the maiden study in the area of system niche consumption. We explored the concept of "niche 
technology," focusing on the SNS context, and developed a measurement. In doing so, we integrated the domains of consciousness, uniqueness, and digital extended self with IS consumption, to better illustrate the usage dynamics of niche systems. We identified the above-mentioned three dimensions of perceived niche, and, across four empirical studies, we supported this conceptualization and developed the instrument. First, we conducted qualitative preliminary focus group interviews. Then, we refined the scale through two longitudinal validation studies (Studies 2 and 3), which provided evidence of the scale's reliability and validity. To assess the predictive and nomological validity of the refined scale, we conducted Study 4 . This research will potentially help IS scholars explore the implications of the emerging and important concept of technology niche for usage behaviors.

\section{References}

Amaldoss, W., \& Jain, S. (2008). Research note-Trading up: A strategic analysis of reference group effects. Marketing Science, 27(5), 932-942.

Bagozzi, R. P., \& Heatherton, T. F. (1994). A general approach to representing multifaceted personality constructs: Application to state self-esteem. Structural Equation Modeling: A Multidisciplinary Journal, 1(1), 35-67.

Bagozzi, R. P., \& Yi, Y. (1988). On the evaluation of structural equation models. Journal of the Academy of Marketing Science, 16(1), 74-94.

Bagozzi, R. (2011). Measurement and meaning in information systems and organizational research: Methodological and philosophical foundations. MIS Quarterly, 35(2), 261-292.

Bajac, H., Palacios, M., \& Minton, E.A. (2018). Consumer-brand congruence and conspicuousness: An international comparison. International Marketing Review, 35(3), 498-517.

Belk, R. W. (1988). Possessions and the extended self. Journal of Consumer Research, 15(2), 139168.

Belk, R. (2018). Ownership: The extended self and the extended object. In Psychological Ownership and Consumer Behavior (pp. 53-67). Springer, Cham.

Berger, J., \& Heath, C. (2008). Who drives divergence? Identity signaling, outgroup dissimilarity, and the abandonment of cultural tastes. Journal of Personality and Social Psychology, 95(3), 593-614.

Bhattacherjee, A. (2001). Understanding information systems continuance: an expectationconfirmation model. MIS Quarterly, 25(3), 351-370.

Brewer, M. B. (1991). The social self: On being the same and different at the same time. Personality and Social Psychology Bulletin, 17(5), 475-482.

Brewer, M. B., \& Pickett, C. L. (2014). The Social Self and Group Identification. In: Forgas, J. P. \& Williams, K. D. (eds.) The Social Self: Cognitive, Interpersonal, and Intergroup perspectives. Hove, East Sussex: Psychology Press.

Chin, W. W. (1998). The partial least squares approach to structural equation modeling. Modern Methods for Business Research, 295(2), 295-336. 
Cho, J. Y., \& Suh, J. (2020) Spatial Color Efficacy in Perceived Luxury and Preference to Stay: An Eye-Tracking Study of Retail Interior Environment. Frontiers in Psychology,11 (2), 115.

Cohen, J. (1968). Weighted kappa: nominal scale agreement provision for scaled disagreement or partial credit. Psychological Bulletin, 70(4), 213.

Darban, M., \& Polites, G. L. (2020). Why Is It Hard to Fight Herding? The Roles of User and Technology Attributes. ACM SIGMIS Database: the DATABASE for Advances in Information Systems, 51(4), 93-122.

Davis, F. D. (1989). Perceived usefulness, perceived ease of use, and user acceptance of information technology. MIS Quarterly, 13(3), 319-340.

Dogan, V., Ozkara, B. Y., \& Dogan, M. (2018). Luxury consumption tendency: conceptualization, scale development and validation. Current Psychology,39, 934-952.

Echols, A., \& Tsai, W. (2005). Niche and performance: the moderating role of network embeddedness. Strategic Management Journal, 26(3), 219-238.

Ello Manifesto (2014). Retrieved April 20, 2018, from https:/ello.co/wtf/about/ello-manifesto/

Ferraro, R., Escalas, J. E., \& Bettman, J. R. (2011). Our possessions, our selves: Domains of selfworth and the possession-self link. Journal of Consumer Psychology, 21(2), 169-177.

Fogliatto, F. S., Da Silveira, G. J., \& Borenstein, D. (2012). The mass customization decade: An updated review of the literature. International Journal of Production Economics, 138(1), 1425.

Fornell, C., \& Larcker, D. F. (1981). Evaluating structural equation models with unobservable variables and measurement error. Journal of Marketing Research, 18(1), 39-50.

Franke, N., \& Schreier, M. (2008). Product uniqueness as a driver of customer utility in mass customization. Marketing Letters, 19(2), 93-107.

Gierl, H., \& Huettl, V. (2010). Are scarce products always more attractive? The interaction of different types of scarcity signals with products' suitability for conspicuous consumption. International Journal of Research in Marketing, 27(3), 225-235.

Jarvis, C. B., MacKenzie, S. B., \& Podsakoff, P. M. (2003). A critical review of construct indicators and measurement model misspecification in marketing and consumer research. Journal of Consumer Research, 30(2), 199-218.

Jetten, J., Spears, R., \& Postmes, T. (2004). Intergroup distinctiveness and differentiation: A meta-analytic integration. Journal of Personality and Social Psychology, 86(6), 862-879.

Kapferer, J. N. (2012). Abundant rarity: The key to luxury growth. Business Horizons, 55(5), 453462.

Kemp, S. (1998). Perceiving luxury and necessity. Journal of Economic Psychology, 19(5), 591-606.

Lee, Y. J., Hosanagar, K., \& Tan, Y. (2015). Do I follow my friends or the crowd? Information cascades in online movie ratings. Management Science, 61(9), 2241-2258.

MacMillan, D. (2012). Lenovo CEO says tablets make up niche market dominated by Apple. Retrieved April 20, 2018, from www.businessweek.com/news/2012-01-13/ lenovo-ceo-says-tablets-make-up-niche-market-dominated-by-apple.html. 
Maier, C., Laumer, S., Weinert, C., \& Weitzel, T. (2015). The effects of technostress and switching stress on discontinued use of social networking services: a study of Facebook use. Information Systems Journal, 25(3), 275-308.

Moore, G. C., \& Benbasat, I. (1991). Development of an instrument to measure the perceptions of adopting an information technology innovation. Information Systems Research, 2(3), 192-222.

Nayal, P., \& Pandey, N. (2020). Digital coupon redemption: Conceptualization, scale development and validation. Australasian Journal of Information Systems, 24(2020), 1-23.

Nunnally, J. C., \& Bernstein, I. H. (1994). Psychometric Theory (3 ${ }^{\text {rd }}$ ed.). New York: McGrawHill, Inc.

Pantzalis, I. (1995). Exclusivity Strategies in Pricing and Brand Extension. Unpublished doctoral dissertation. University of Arizona, Tucson, AZ.

Parkinson, B., Millard, D. E., O'Hara, K., \& Giordano, R. (2018). The digitally extended self: A lexicological analysis of personal data. Journal of Information Science, 44(4), 552-565.

Parrish, E. (2010). Retailers' use of niche marketing in product development. Journal of Fashion Marketing and Management, 14 (4), 546-561.

Patsiaouras, G., \& Fitchett, J.A. (2012). The evolution of conspicuous consumption. Journal of Historical Research in Marketing, 4(1), 154-176.

Polites, G. L., \& Karahanna, E. (2012). Shackled to the status quo: The inhibiting effects of incumbent system habit, switching costs, and inertia on new system acceptance. MIS Quarterly, 36 (1), pp. 21-42.

Porter, M. E. (1980). Competitive Strategy. Free Press: New York.

Rogers, E. M. (2003). Diffusion of innovations ( $5^{\text {th }}$ ed.). Free Press: New York.

Roux, E., Tafani, E., \& Vigneron, F. (2017). Values associated with luxury brand consumption and the role of gender. Journal of Business Research, 71, 102-113.

Samhan, B. (2018). Revisiting technology resistance: Current insights and future directions. Australasian Journal of Information Systems, 22(2018), 1-11.

Schaefers, T. (2014). Standing out from the crowd: niche product choice as a form of conspicuous consumption. European Journal of Marketing, 48(9), 1805-1827.

Sharma R., Yetton P., \& Crawford J. (2009). Estimating the effect of common method variance: The method-Method pair technique with an Illustration from TAM Research. MIS Quarterly, 33(3), 473-490.

Shea, C. (2018). Is a social network that doesn't share user data possible? We asked someone who's trying. Retrieved from https://www.vox.com/conversations/2018/3/27/17168790/ ello-facebook-alternative-data-privacy-cambridge-analytica-deletefacebook.

Snyder, \& Fromkin, H. (2012). Uniqueness: The Pursuit of Difference. Plenum: New York, NY.

Straub, D., Boudreau, M. C., \& Gefen, D. (2004). Validation guidelines for IS positivist research. Communications of the Association for Information Systems, 13(1), 24, 380-427 
Tan, T. F., Netessine, S., \& Hitt, L. (2017). Is Tom Cruise threatened? an empirical study of the impact of product variety on demand concentration. Information Systems Research, 28(3), 643-660.

Thatcher, J. B., Wright, R. T., Sun, H., Zagenczyk, T. J., \& Klein, R. (2018). Mindfulness in information technology use: Definitions, distinctions, and a new measure. MIS Quarterly, 42(3), 831-848.

Venkatesh, V., Morris, M. G., Davis, G. B., \& Davis, F. D. (2003). User acceptance of information technology: Toward a unified view. MIS Quarterly, 27(3), 425-478.

Vigneron, F., \& Johnson, L. W. (2017). Measuring Perceptions of Brand Luxury. In Advances in Luxury Brand Management (pp. 199-234). Palgrave Macmillan, Cham.

Villanova, D. (2019). The extended self, product valuation, and the endowment effect. AMS Review, 9(3), 357-371.

Wan, X., Wang, T., \& Wu, J. (2018). I'll follow the minority: The effects of sales level on purchase intention of self-expressive products. Frontiers in Psychology, 9(1), 1135-1147.

Wang, C., \& Lee, M. K. (2020). Why We Cannot Resist Our Smartphones: Investigating Compulsive Use of Mobile SNS from a Stimulus-Response-Reinforcement Perspective. Journal of the Association for Information Systems, 21(1), 175-200.

Whitehead, M. (2020). Why people leave Facebook - and what it tells us about the future of social media. Retrieved from https://theconversation.com/why-people-leave-facebookand-what-it-tells-us-about-the-future-of-social-media-128952

\section{Appendix A}

Table A1. Items and Factor Loadings (Study 2)

\begin{tabular}{|l|c|c|c|c|c|c|}
\hline & CNF & Conspicuousness & Uniqueness & $\begin{array}{c}\text { Digital } \\
\text { extended self }\end{array}$ & TTF & NE \\
\hline CNF1 & .785 & .051 & .111 & .204 & .082 & .011 \\
\hline CNF2 & .884 & .018 & .089 & .221 & .173 & .030 \\
\hline CNF3 & .870 & .108 & .231 & .198 & .103 & .085 \\
\hline CNF4 & .709 & .185 & .031 & .201 & .215 & .151 \\
\hline NCH-CN1 & -.026 & .859 & .249 & .218 & -.053 & .011 \\
\hline NCH-CN2 & .060 & .852 & .261 & .235 & -.087 & -.041 \\
\hline NCH-CN3 & .009 & .830 & .311 & .161 & -.121 & -.012 \\
\hline NCH-UQ1 & .201 & .234 & .831 & .200 & -.102 & -.077 \\
\hline NCH-UQ2 & -.012 & .261 & .873 & .222 & -.089 & .121 \\
\hline NCH-UQ4 & .098 & .238 & .829 & .207 & -.101 & .098 \\
\hline NCH-DG2 & .012 & .183 & .214 & .822 & -.203 & .171 \\
\hline NCH-DG3 & -0.09 & .267 & .130 & .871 & .098 & .113 \\
\hline TTF1 & .085 & -.025 & -.037 & .201 & .719 & .045 \\
\hline TTF2 & .051 & -.076 & .121 & .012 & .803 & .027 \\
\hline TTF3 & .114 & -.130 & .091 & .090 & .839 & .048 \\
\hline TTF4 & .077 & -.107 & .120 & .230 & .824 & .106 \\
\hline TTF5 & .102 & -.067 & -.122 & .201 & .808 & .045 \\
\hline TTF6 & .037 & -.026 & .231 & -.121 & .785 & .080 \\
\hline TTF7 & .066 & -.043 & .101 & .099 & .739 & .121 \\
\hline
\end{tabular}




\begin{tabular}{|l|c|c|c|c|c|c|}
\hline TTF8 & .177 & -.125 & -.091 & .120 & .723 & .091 \\
\hline NE1 & .105 & -.010 & .201 & .056 & .099 & .779 \\
\hline NE2 & .175 & .051 & .089 & -.034 & .017 & .711 \\
\hline NE3 & .046 & -.103 & -.100 & .089 & .031 & .841 \\
\hline NE4 & .058 & -.067 & -.009 & .209 & .038 & .805 \\
\hline NE5 & .191 & -.250 & -.121 & .221 & .090 & .735 \\
\hline
\end{tabular}

Notes: Principal Components with Varimax rotation

Analysis conducted using SPSS 16.0

CNF: Confirmation; $N C H=$ Perceived Niche, $C N=$ Conspicuousness, $U Q=$ Uniqueness, $D G=$ Digital extended self, TTF = Task-Technology Fit; NE = Network effect.

Table A2. Item Loadings, Means and Standard Deviations

\begin{tabular}{|l|c|c|c|c|c|c|}
\hline \multirow{2}{*}{ Item } & \multicolumn{3}{|c|}{ Study 2 } & \multicolumn{3}{c|}{ Study 3 } \\
\cline { 2 - 7 } & $\begin{array}{c}\text { Standardized } \\
\text { Item Loading }\end{array}$ & Mean & S.D. & $\begin{array}{c}\text { Standardized } \\
\text { Item Loading }\end{array}$ & Mean & S.D. \\
\hline NCH-CN1 & 0.86 & 4.54 & 1.83 & 0.83 & 5.02 & 1.10 \\
\hline NCH-CN2 & 0.88 & 4.81 & 1.97 & 0.87 & 4.78 & 1.05 \\
\hline NCH-CN3 & 0.87 & 4.37 & 1.79 & 0.81 & 5.01 & 0.99 \\
\hline NCH-UQ1 & 0.83 & 4.49 & 1.74 & 0.87 & 4.87 & 1.61 \\
\hline NCH-UQ2 & 0.92 & 4.50 & 1.38 & 0.87 & 4.91 & 1.32 \\
\hline NCH-UQ4 & 0.86 & 4.71 & 1.77 & 0.76 & 5.03 & 1.06 \\
\hline NCH-DG2 & 0.81 & 4.02 & 1.43 & 0.83 & 5.11 & 1.31 \\
\hline NCH-DG3 & 0.80 & 4.30 & 1.40 & 0.77 & 4.70 & 1.20 \\
\hline
\end{tabular}

Notes: $\quad N C H=$ Perceived Niche, $C N=$ Conspicuousness, $U Q=$ Uniqueness, $D G=$ Digital extended self

Table A3. Construct Means, Standard Deviations, Reliabilities, and Correlations (Study 2)

\begin{tabular}{|c|c|c|c|c|c|c|c|c|}
\hline Construct & Mean & S.D. & AVE & CR & Cronbach's Alpha & 1 & 2 & 3 \\
\hline Construct & Mean & S.D. & AVE & CR & Cronbach's Alpha & 1 & 2 & 3 \\
\hline 1. NCH-CN & 4.35 & 1.23 & 0.76 & 0.90 & 0.89 & 0.87 & & \\
\hline 2. NCH-UQ & 4.54 & 1.15 & 0.71 & 0.91 & 0.89 & 0.53 & 0.84 & \\
\hline 3. NCH-DG & 5.07 & 1.30 & 0.62 & 0.83 & 0.79 & 0.47 & 0.45 & 0.79 \\
\hline
\end{tabular}

Notes: $\quad A V E=$ Average Variance Extracted, square-roots of the AVEs appear in bold along the diagonal of the correlations. $\mathrm{NCH}=$ Perceived Niche, $\mathrm{CN}=$ Conspicuousness, $U Q=$ Uniqueness, $D G=$ Digital extended self

Table A4. Item Measures (Study 4)

\begin{tabular}{|c|c|c|c|c|}
\hline & Construct \& Item & Mean & S.D. & $\begin{array}{c}\text { Standardized } \\
\text { Item } \\
\text { Loading } \\
\end{array}$ \\
\hline \multicolumn{4}{|c|}{ Perceived Niche: Conspicuousness $(\mathrm{CN})^{\mathrm{a}}$} & \\
\hline CN1 & Behance is designed for an elite cluster of SNS users. & 4.98 & 1.87 & 0.84 \\
\hline CN2 & I use Behance because it enhances my social image. & 4.43 & 2.00 & 0.88 \\
\hline CN3 & Behance's content reflects its high status. & 4.27 & 2.01 & 0.86 \\
\hline \multicolumn{4}{|c|}{ Perceived Niche: Uniqueness $(\mathrm{UQ})^{\mathrm{a}}$} & \\
\hline UQ1 & Behance is distinct from other SNSs. & 4.15 & 1.85 & 0.72 \\
\hline UQ2 & Behance can be used in a different way compared to other SNSs. & 4.46 & 1.71 & 0.89 \\
\hline UQ4 & Behance's content is different from other SNSs. & 4.44 & 1.68 & 0.88 \\
\hline \multicolumn{4}{|c|}{ Perceived Niche: Digital extended self (DG) ${ }^{a}$} & \\
\hline DG2 & I can express myself fully using Ello. & 4.11 & 1.46 & 0.88 \\
\hline
\end{tabular}




\begin{tabular}{|c|c|c|c|c|}
\hline DG3 & Behance allows me to express myself the way I could not by other SNSs. & 4.30 & 1.42 & 0.87 \\
\hline \multicolumn{5}{|c|}{ Continuance Intention ${ }^{b}$} \\
\hline Con1 & I intend to continue using Ello rather than discontinue its use. & 5.05 & 1.23 & 0.78 \\
\hline Con2 & $\begin{array}{l}\text { My intentions are to continue using Ello rather than use any alternative } \\
\text { means. }\end{array}$ & 4.98 & 1.50 & 0.86 \\
\hline Con3 & If I could, I would like to discontinue my use of Ello. ${ }^{c}$ & 4.82 & 1.39 & 0.77 \\
\hline \multicolumn{5}{|c|}{ Perceived Ease of Use ${ }^{a}$} \\
\hline PEU1 & My interaction with Ello is clear and understandable. & 3.78 & 2.94 & 0.82 \\
\hline PEU2 & Interacting with Ello does not require a lot of mental effort. & 3.45 & 1.55 & 0.73 \\
\hline PEU3 & I find it easy to get Ello to do what I want it to do. & 3.52 & 2.11 & 0.91 \\
\hline PEU4 & I find Ello to be easy to use. & 3.29 & 1.88 & 0.81 \\
\hline \multicolumn{5}{|c|}{ Perceived Usefulness ${ }^{a}$} \\
\hline PU1 & Ello helps me to accomplish tasks more quickly. & 3.78 & 1.68 & 0.73 \\
\hline PU2 & Ello improves the quality of the tasks I do. & 3.75 & 1.85 & 0.79 \\
\hline PU3 & Ello gives me greater control over my tasks. & 3.81 & 1.77 & 0.85 \\
\hline PU4 & Ello enhances my effectiveness in my tasks. & 3.89 & 1.66 & 0.83 \\
\hline
\end{tabular}

Notes: $\quad{ }^{a}$ Collected in Time 2

${ }^{b}$ Collected in Time 3

${ }^{c}$ Reverse coded

Items were measured on a 1 = Strongly Disagree, 7 = Strongly Agree format

Table A5. AVs, Reliabilities, and Correlations (Study 4)

\begin{tabular}{|l|l|l|l|l|l|l|l|l|l|l|}
\hline \multicolumn{1}{|c|}{ Item } & Mean & S.D. & CR & AVE & 1 & 2 & 3 & 4 & 5 & 6 \\
\hline 1. NCH-CN & 4.26 & 1.23 & 0.90 & 0.75 & $\mathbf{0 . 8 6}$ & & & & & \\
\hline 2. NCH-UQ & 5.80 & 1.31 & 0.87 & 0.70 & 0.53 & $\mathbf{0 . 8 3}$ & & & & \\
\hline 3. NCH-DG & 4.83 & 1.09 & 0.87 & 0.78 & 0.50 & 0.56 & $\mathbf{0 . 8 8}$ & & & \\
\hline 4. CON & 5.49 & 1.23 & 0.80 & 0.57 & 0.39 & 0.09 & 0.37 & $\mathbf{0 . 7 6}$ & & \\
\hline 5. PEU & 4.81 & 1.40 & 0.90 & 0.70 & 0.08 & 0.17 & 0.16 & 0.37 & $\mathbf{0 . 8 3}$ & \\
\hline 6. PU & 4.77 & 1.10 & 0.86 & 0.62 & -0.02 & -0.10 & 0.05 & 0.31 & 0.51 & $\mathbf{0 . 7 9}$ \\
\hline
\end{tabular}

Notes: The correlations between all pairs of first-order constructs of perceived niche fall below 0.90 (Bagozzi et al. 1991), indicating distinct dimensions.

AVE $=$ Average Variance Extracted

Square-roots of the AVEs appear in bold along the diagonal of the correlations.

$\mathrm{NCH}=$ Perceived Niche, $\mathrm{CN}=$ Conspicuousness, $U Q=$ Uniqueness, $D G=$ Digital extended self, Con = Continuance Intention, $P E U=$ Perceived Ease of Use, $P U=$ Perceived Usefulness.

Measurement Model Fit Statistics Chi-square 196.40 with d.f. 137, CFI =.98, RMSEA .38

Copyright: (C) 2021 authors. This is an open-access article distributed under the terms of the Creative Commons Attribution-NonCommercial 3.0 Australia License, which permits noncommercial use, distribution, and reproduction in any medium, provided the original author and AJIS are credited. 


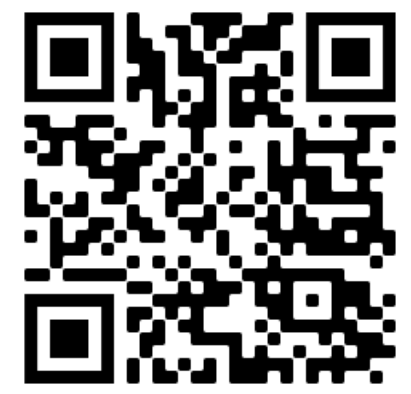

